\title{
Grain orientation studies in YBCO superconductors by molten salt synthesis
}

\author{
SUDHAKAR GOPALAKRISHNAN and WALTER A \\ SCHULZE \\ New York State College of Ceramics, Alfred University, Alfred, NY 14802, USA
}

\begin{abstract}
The molten salt or the flux method is utilized in this study to fabricate a grainoriented $\mathrm{YBa}_{2} \mathrm{Cu}_{3} \mathrm{O}_{7-x}$ superconductor. The formation of $\mathrm{YBa}_{2} \mathrm{Cu}_{3} \mathrm{O}_{7-x}$ in the presence of molten salts of $\mathrm{Na}, \mathrm{K}, \mathrm{Li}$ belonging to chloride and iodide systems does not appear feasible due to the instability of the superconducting phase in these salt systems. Studies using the "green phase," $\mathrm{Y}_{2} \mathrm{BaCuO}_{5}$, as seed crystals suggest a two-stage approach in the formation of $\mathrm{YBa}_{2} \mathrm{Cu}_{3} \mathrm{O}_{7-x}$. The process uses $\mathrm{Y}_{2} \mathrm{BaCuO}_{5}$ formed by molten salt synthesis which has been observed to be stable in water and against most of the salts. The 211 crystals can be mixed with oxides and converted to 123 . Analysis of X-ray data and SEM micrographs indicates a certain degree of grain orientation, which can be further enhanced by tape-casting or sot-forging.
\end{abstract}

Keywords. Grain orientation; molten salt synthesis; YBCO superconductors.

\section{Introduction}

The existing anisotropy in the current density of $\mathrm{YBa}_{2} \mathrm{Cu}_{3} \mathrm{O}_{7-x}$ (Dinger et al 1987) warrants a grain orientation processing which yields 'textured' microstructure with the aim to enhance the current density of the ceramic. Molten salt processing can yield particles with shape anisotropy which are subsequently aligned by techniques such as tape-casting. This technique has been applied successfully on a variety of ferroelectric (Kimura and Yamaguchi 1987; Lin et al 1983) systems.

Attempts at molten salt synthesis of $\mathrm{YBa}_{2} \mathrm{Cu}_{3} \mathrm{O}_{7-x}$ in other ceramic systems have been largely unsuccessful. Studies by Decker $e$ al (1988) revealed the instability of the superconducting phase in $\mathrm{NaCl}-\mathrm{KCl}, \mathrm{BaCl}_{2}-\mathrm{CuCl}_{2}, \mathrm{CuCl}_{2}$, and $\mathrm{Na}_{2} \mathrm{SO}_{4}-\mathrm{K}_{2} \mathrm{SO}_{4}$ salts. Knorr and Raeder (1989) have shown that the stability of the $\mathrm{YBa}_{2} \mathrm{Cu}_{3} \mathrm{O}_{7-x}$ phase is favoured in salt systems with small anion and large cation sizes. Their other studies also indicate the instability of $\mathrm{YBa}_{2} \mathrm{Cu}_{3} \mathrm{O}_{7-x}$ phase in molten chloride salts containing $\mathrm{LiCl}$ or dichlorides. $\mathrm{YBa}_{2} \mathrm{Cu}_{3} \mathrm{O}_{7-x}$ in powdered form reacts vigorously at room temperature with water (Barns and Laudise 1987). It is also shown that the green phase $\mathrm{Y}_{2} \mathrm{BaCuO}_{5}$ is one of the decomposition products of the reaction of $\mathrm{YBa}_{2} \mathrm{Cu}_{3} \mathrm{O}_{7-x}$ with water. Molten salt processing of $\mathrm{YBa}_{2} \mathrm{Cu}_{3} \mathrm{O}_{7-x}$ requires a complex process for removal of the salts. Success has been reported in the single crystal growth of $\mathrm{YBa}_{2} \mathrm{Cu}_{3} \mathrm{O}_{7-x}$ from oxide melts with excess $\mathrm{CuO}$ (Damento et al 1987) and in bulk form from a fused eutectic of sodium and potassium hydroxides (Coppa et al 1989).

The instability of $\mathrm{YBa}_{2} \mathrm{Cu}_{3} \mathrm{O}_{7-x}$ in the chloride and iodide salt melts is reported here. A two-stage approach to the formation of $\mathrm{YBa}_{2} \mathrm{Cu}_{3} \mathrm{O}_{7-x}$ by utilizing the green phase $\mathrm{Y}_{2} \mathrm{BaCuO}_{5}$ formed by molten salt synthesis as seed crystals is also reported. 


\section{Experimental procedures}

\section{$2.1 \mathrm{YBa}_{2} \mathrm{Cu}_{3} \mathrm{O}_{7-x}$-salt equilibrium}

Solid-state reacted $\mathrm{YBa}_{2} \mathrm{Cu}_{3} \mathrm{O}_{7-x}$ was prepared from reagent grade $\mathrm{Y}_{2} \mathrm{O}_{3}, \mathrm{BaCO}_{3}$ and $\mathrm{CuO}$. The powders were calcined at $960^{\circ} \mathrm{C}$ for $12 \mathrm{~h}$ in oxygen atmosphere and annealed at $530^{\circ} \mathrm{C}$ for $6 \mathrm{~h}$. The presence of pure 123 orthorhombic phase was confirmed by $\mathrm{X}$-ray diffraction. The $\mathrm{YBa}_{2} \mathrm{Cu}_{3} \mathrm{O}_{7-x}$ was then mixed with the various salt systems and heattreated in closed magnesia crucibles. The melting points for each system as determined from the phase diagram (Levin et al 1969) was considered in choosing the temperatures for heat treatment. Table 1 gives the various salt systems investigated and the various phases obtained. The temperature, exposure time and the weight ratio of salt to the 123 powder are also reported here. The eutectic salt mixtures of two different salts contained $50 \mathrm{~mol} \%$ of each.

\section{$2.2 \mathrm{Y}_{2} \mathrm{BaCuO}_{5}$-salt equilibrium}

The experimental method is the same as reported for $\mathrm{YBa}_{2} \mathrm{Cu}_{3} \mathrm{O}_{7-x}$. In this case the equilibrium was approached from both ends. Tables 2 and 3 give all the pertinent details. The salt systems investigated are the chlorides, sulphates of $\mathrm{Na}, \mathrm{K}$ and $\mathrm{Li}$. The high stability of $\mathrm{Y}_{2} \mathrm{BaCuO}_{5}$ in water enabled easy removal of the salts by repeated washing with water. $X$-ray diffraction studies were used to confirm the complete removal of the salts. The resultant pure $\mathrm{Y}_{2} \mathrm{BaCuO}_{5}$ was mixed with reagent grade $\mathrm{BaCO}_{3}$ and $\mathrm{CuO}$ in the required molar proportions as given by the following reaction (Ruckenstein et al 1989):

$$
\mathrm{Y}_{2} \mathrm{BaCuO}_{5}+3 \mathrm{BaCO}_{3}+5 \mathrm{CuO}=2 \mathrm{YBa}_{2} \mathrm{Cu}_{3} \mathrm{O}_{7-x}+3 \mathrm{CO}_{2} \text {. }
$$

The batch was calcined at $960^{\circ} \mathrm{C}$ for $12 \mathrm{~h}$ and annealed at $530^{\circ} \mathrm{C}$ for $6 \mathrm{~h}$ in oxygen atmosphere. In another method the batch was mixed with binders, solvents, and plasticizers, tape-casted, laminated and sintered. $X$-ray diffraction analysis revealed the presence of $\mathrm{YBa}_{2} \mathrm{Cu}_{3} \mathrm{O}_{7-x}$. A moderate degree of orientation could be achieved by this method.

Table.1. Stability of preformed 123 phase in molten salt systems

\begin{tabular}{llllll}
\hline $\begin{array}{l}\text { Ratio } \\
\text { Salt:123 }\end{array}$ & $\begin{array}{c}\text { Salt } \\
\text { systems }\end{array}$ & $\begin{array}{c}\text { Temp } \\
\left({ }^{\circ} \mathrm{C}\right)\end{array}$ & $\begin{array}{c}\text { Time } \\
(\mathrm{h})\end{array}$ & \multicolumn{2}{c}{$\begin{array}{c}\text { Resulting phases } \\
\text { Oxides }\end{array}$} \\
\hline $1: 1$ & $\mathrm{NaCl}-\mathrm{KCl}$ & 850 & 2 & $211,123_{t}$ & $\mathrm{NaCl}, \mathrm{KCl}$ \\
$1: 1$ & $\mathrm{LiCl}$ & 750 & 2 & $\mathrm{Cu}_{2} \mathrm{Y}_{2} \mathrm{O}_{5}$ & $\mathrm{BaCl}_{2}$ \\
$1: 1$ & $\mathrm{KI}$ & 975 & 3 & $211,123_{t}$ & $\mathrm{KI}$ \\
$1: 1$ & $\mathrm{NaI}$ & 975 & 3 & $211,123_{t}$ & $\mathrm{NaI}$ \\
$1: 1$ & $\mathrm{NaI}-\mathrm{KI}$ & 975 & 3 & $211,123_{t}$ & $\mathrm{KI}, \mathrm{NaI}$ \\
$1: 1$ & $\mathrm{KI}$ & 750 & 4 & $\mathrm{Y}_{2} \mathrm{O}_{3}$ & $\mathrm{KI}$ \\
$2: 1$ & $\mathrm{KI}$ & 750 & 4 & $123_{t}$ & $\mathrm{KI}$ \\
\hline
\end{tabular}


Table 2. Stability of preformed 211 phase in molten salt systems

\begin{tabular}{|c|c|c|c|c|c|}
\hline \multirow{2}{*}{$\begin{array}{l}\text { Ratio } \\
\text { Salt:211 }\end{array}$} & \multirow{2}{*}{$\begin{array}{c}\text { Salt } \\
\text { systems }\end{array}$} & \multirow{2}{*}{$\begin{array}{l}\text { Temp. } \\
\left({ }^{\circ} \mathrm{C}\right)\end{array}$} & \multirow{2}{*}{$\begin{array}{c}\text { Time } \\
\text { (h) }\end{array}$} & \multicolumn{2}{|c|}{ Resulting phases } \\
\hline & & & & Oxides & Other phases \\
\hline $1: 1$ & $\mathrm{NaCl}$ & 825 & 3 & 211 & $\mathrm{NaCl}$ \\
\hline $1: 1$ & $\mathrm{KCl}$ & 825 & 3 & 211 & $\mathrm{KCl}$ \\
\hline $1: 1$ & $\mathrm{LiCl}$ & 825 & 3 & $\mathrm{Cu}_{2} \mathrm{Y}_{2} \mathrm{O}_{5}, \mathrm{Y}_{2} \mathrm{O}_{3}$ & $\mathrm{LiCl}$ \\
\hline $1: 1$ & $\mathrm{NaCl}-\mathrm{KCl}-\mathrm{LiCl}$ & 825 & 3 & $\mathrm{Cu}_{2} \mathrm{Y}_{2} \mathrm{O}_{5}, \mathrm{Y}_{2} \mathrm{O}_{3}$ & $\mathrm{NaCl}, \mathrm{KCl}$ \\
\hline $1: 1$ & $\mathrm{Li}_{2} \mathrm{SO}_{4}$ & 975 & 3 & $\mathrm{Cu}_{2} \mathrm{Y}_{2} \mathrm{O}_{5}$ & $\mathrm{BaSO}_{4}$ \\
\hline $1: 1$ & $\mathrm{Na}_{2} \mathrm{SO}_{4}$ & 975 & 3 & 211 & $\mathrm{Na}_{2} \mathrm{SO}_{4}$ \\
\hline $1: 1$ & $\mathrm{~K}_{2} \mathrm{SO}_{4}$ & 975 & 3 & 211 & $\mathrm{~K}_{2} \mathrm{SO}_{4}$ \\
\hline $1: 1$ & $\mathrm{Li}_{2} \mathrm{SO}_{4}-\mathrm{Na}_{2} \mathrm{SO}_{4}-\mathrm{K}_{2} \mathrm{SO}_{4}$ & 975 & 3 & $211, \mathrm{Cu}_{2} \mathrm{Y}_{2} \mathrm{O}_{5}$ & $\mathrm{BaSO}_{4}$ \\
\hline $1: 1$ & $\mathrm{Na}_{2} \mathrm{SO}_{4}$ & 1050 & 4 & 211 & $\mathrm{Na}_{2} \mathrm{SO}_{4 i}$ \\
\hline $1: 1$ & $\mathrm{~K}_{2} \mathrm{SO}_{4}$ & 1050 & 4 & 211 & $\mathrm{~K}_{2} \mathrm{SO}_{4 t}$ \\
\hline $1: 1$ & $\mathrm{Li}_{2} \mathrm{SO}_{4}-\mathrm{Na}_{2} \mathrm{SO}_{4}-\mathrm{K}_{2} \mathrm{SO}_{4}$ & 1050 & 4 & $\mathrm{Y}_{2} \mathrm{O}_{3}$ & $\ldots$ \\
\hline $1: 1$ & $\mathrm{Na}_{2} \mathrm{SO}_{4}$ & 1100 & 4 & $211, \mathrm{Y}_{2} \mathrm{O}_{3}$ & $\mathrm{Na}_{2} \mathrm{SO}_{4 t}$ \\
\hline $1: 1$ & $\mathrm{~K}_{2} \mathrm{SO}_{4}$ & 1100 & 4 & $211, \mathrm{Y}_{2} \mathrm{O}_{3}$ & $\mathrm{~K}_{2} \mathrm{SO}_{4 t}$ \\
\hline $1: 1$ & $\mathrm{NaCl}-\mathrm{KCl}$ & 900 & 2 & 211 & $\mathrm{NaCl}-\mathrm{KCl}$ \\
\hline $2: 1$ & $\mathrm{NaCl}-\mathrm{KCl}$ & 900 & 2 & 211 & $\mathrm{NaCl}-\mathrm{KCl}$ \\
\hline $3: 1$ & $\mathrm{NaCl}-\mathrm{KCl}$ & 900 & 2 & 211 & $\mathrm{NaCl}-\mathrm{KCl}$ \\
\hline
\end{tabular}

Table 3. Stability of 211 phase in precursors-salt systems

\begin{tabular}{lccccc}
\hline $\begin{array}{l}\text { Ratio } \\
\text { Salt:211 }\end{array}$ & $\begin{array}{c}\text { Salt } \\
\text { systems }\end{array}$ & $\begin{array}{c}\text { Temp } \\
\left({ }^{\circ} \mathrm{C}\right)\end{array}$ & $\begin{array}{c}\text { Time } \\
\text { (h) }\end{array}$ & Oxides & $\begin{array}{c}\text { Resulting phases } \\
\text { Other phases }\end{array}$ \\
\hline $1: 1$ & $\mathrm{NaCl}-\mathrm{KCl}$ & 850 & 4 & $\mathrm{Cu}_{2} \mathrm{Y}_{2} \mathrm{O}_{5}, \mathrm{Y}_{2} \mathrm{O}_{3}$ & $\mathrm{BaCO}_{3}, \mathrm{NaCl}, \mathrm{KCl}$ \\
$1: 1$ & $\mathrm{NaCl}-\mathrm{KCl}$ & 1000 & 4 & 211 & $\mathrm{NaCl}, \mathrm{KCl}$ \\
$1: 1$ & $\mathrm{NaCl}$ & 850 & 3 & 211 & $\mathrm{NaCl}$ \\
\hline
\end{tabular}

\section{Results and discussion}

\section{$3.1 \mathrm{YBa}_{2} \mathrm{Cu}_{3} \mathrm{O}_{7-x}$-salt equilibrium}

Our studies have shown that the $\mathrm{YBa}_{2} \mathrm{Cu}_{3} \mathrm{O}_{7-x}$ superconducting phase degraded in all the salt systems we have investigated so far. The trace amount of the 123 phase belongs to the tetragonal system and exhibited no superconducting behaviour. There was an appreciable loss of weight on heat treatment of mixtures that contained salts of lithium. The green phase appeared as a resultant phase in most of the experiments. This further confirmed the highly stable nature of the $\mathrm{Y}_{2} \mathrm{BaCuO}_{5}$ phase.

\section{2 $\mathrm{Y}_{2} \mathrm{BaCuO}_{5}$-salt equilibrium}

Tables 2 and 3 show the stability of $\mathrm{Y}_{2} \mathrm{BaCuO}_{5}$ phase in most of the salt systems. The green phase was observed to degrade in those salt systems that contained lithium salts. A higher temperature of heat treatment and/or higher exposure time resulted in higher amounts of $\mathrm{Y}_{2} \mathrm{BaCuO}_{5}$ and lesser amounts of the salt phases. Figure 1 gives the XRD patterns of the three samples prepared with performed $\mathrm{Y}_{2} \mathrm{BaCuO}_{5}$ powder and the 


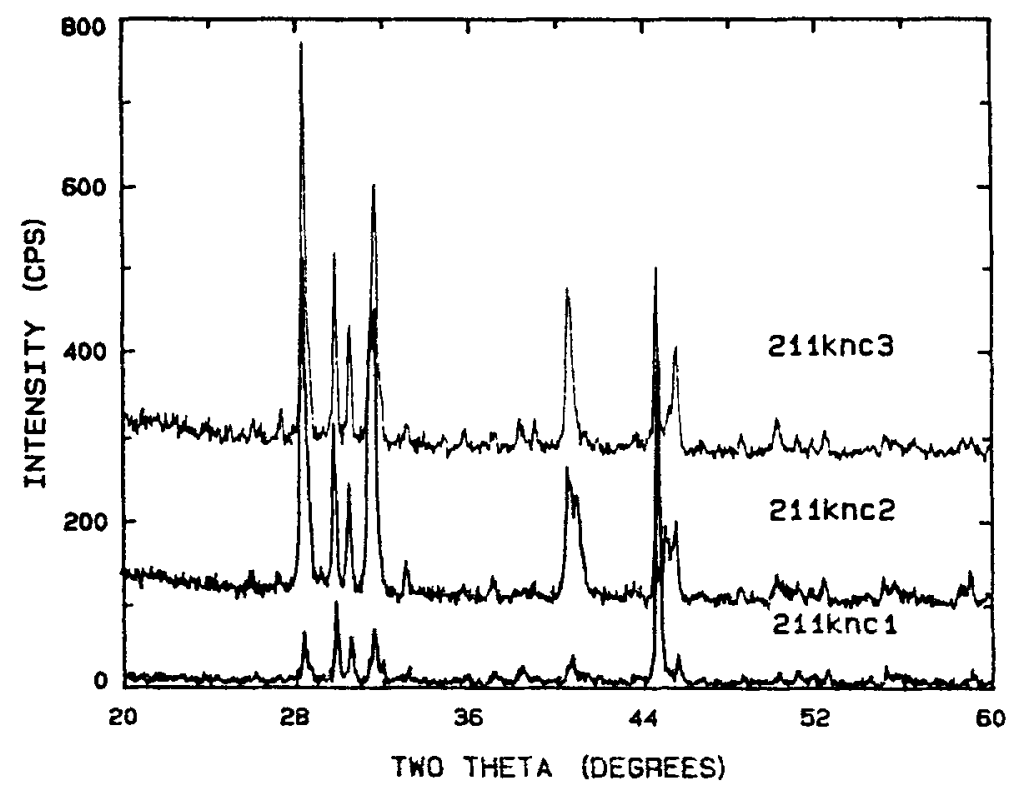

Figure 1. XRD patterns for heat-treated samples of preformed $\mathrm{Y}_{2} \mathrm{BaCuO}_{5}$ and Eutectic salt mixture of $\mathrm{NaCl}-\mathrm{KCl}$ with salt-to-oxide ratios being 1,2, and 3 respectively.

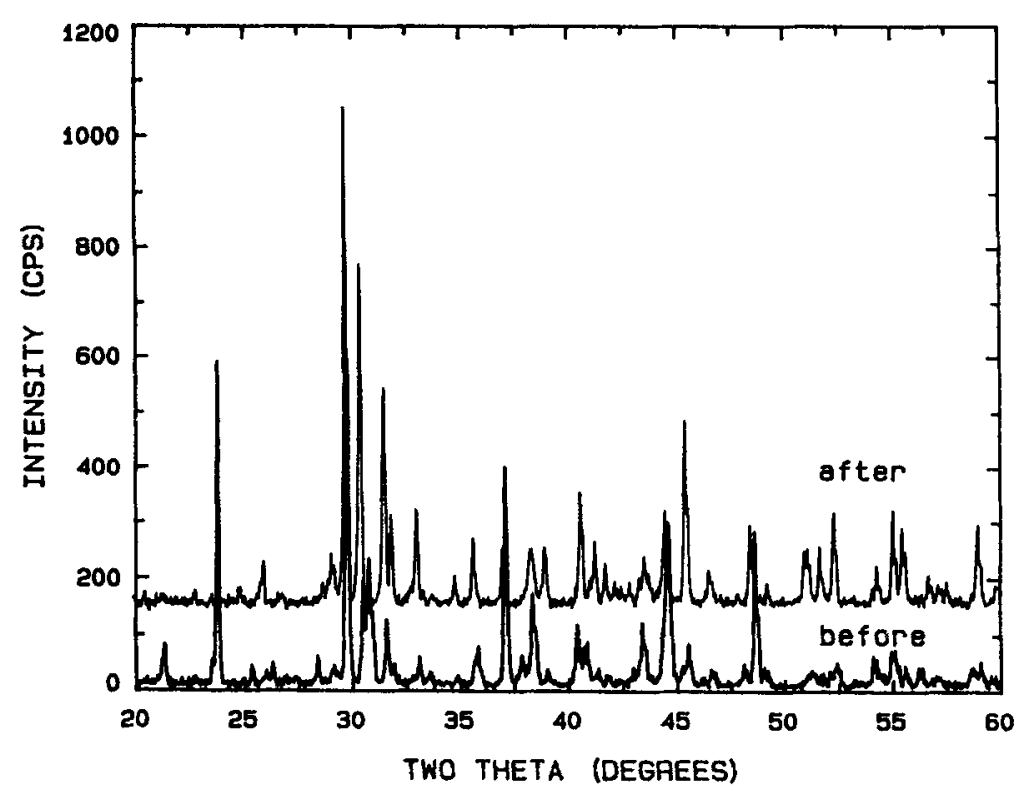

Figure 2. XRD patterns for samples of $\mathrm{Y}_{2} \mathrm{BaCuO}_{5}$ formed by flux method before and after washing with water.

eutectic salt mixture of $\mathrm{NaCl}-\mathrm{KCl}$. The patterns are for increasing order of salt-to-oxide ratio. Repeated washing with water resulted in pure 211 phase as confirmed by XRD. Figure 2 gives the XRD patterns for two samples, one prior to washing in water and the other after washing. The absence of the salt peaks can be easily observed.

The resultant powders after the two-stage process revealed a phase pure 


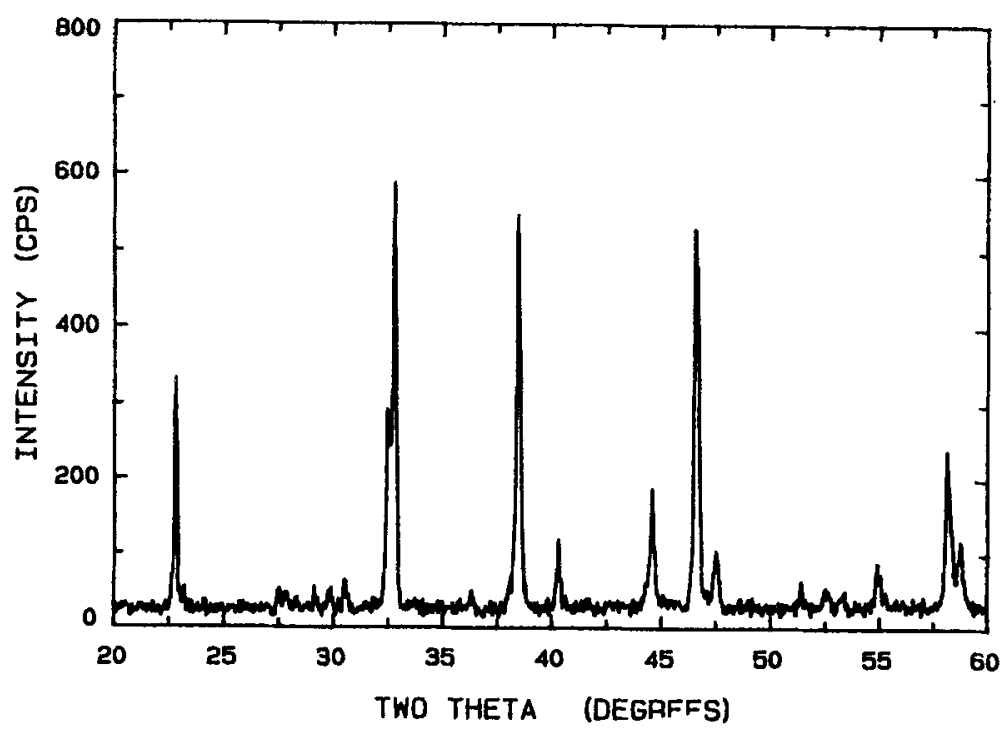

Figure 3. $\mathrm{XRD}$ pattern for $\mathrm{YBa}_{2} \mathrm{Cu}_{3} \mathrm{O}_{7-x}$ formed from calcination of $\mathrm{Y}_{2} \mathrm{BaCuO}_{6}$ with $\mathrm{BaCO}_{3}$ and $\mathrm{CuO}$.

$\mathrm{YBa}_{2} \mathrm{Cu}_{3} \mathrm{O}_{7-x}$ with no or very little of $\mathrm{Y}_{2} \mathrm{BaCuO}_{5}$ as an impurity phase. Figure 3 gives the XRD pattern of $\mathrm{YBa}_{2} \mathrm{Cu}_{3} \mathrm{O}_{7-x}$ sample formed from calcining the batch of $\mathrm{Y}_{2} \mathrm{BaCuO}_{5}$ with $\mathrm{BaCO}_{3}$ and $\mathrm{CuO}$. Tape-casted samples also revealed a phase pure $\mathrm{YBa}_{2} \mathrm{Cu}_{3} \mathrm{O}_{7-x}$.

\section{Conclusions}

$\mathrm{YBa}_{2} \mathrm{Cu}_{3} \mathrm{O}_{7-x}$ superconducting phase degraded in all the salt systems we investigated. The 123 phase obtained in trace quantities belonged to the tetragonal system. The $\mathrm{Y}_{2} \mathrm{BaCuO}_{5}$ showed a better stability in the salts and facilitated in the easy removal of the salts. There is a distinct advantage in the two-stage approach and further work is needed in this area mainly for growing crystals of $\mathrm{Y}_{2} \mathrm{BaCuO}_{5}$ to be later used as seed crystals for the formation of $\mathrm{YBa}_{2} \mathrm{Cu}_{3} \mathrm{O}_{7-x}$.

\section{References}

Barns R L and Laudise R A 1987 Appl. Phys. Lett. 511373

Coppa N, Nichols D H, Schwegler J W, Crow J E, Myer G H and Salomon R E 1989 J. Mater. Res. 41307 Damento M A, Gschneider K A Jr and McCallum R W 1987 Appl. Phys. Lett. 51890

Decker C T, Seth V K and Schulze W A 1988 in Advanced superconductors II (ed.) M F Yan (Ohio: Amerivan Ceramic Society)

Dinger T R, Worthington T K, Gallagher W J and Sandstrom R L 1987 Phys. Rev. Lett. 582687

Kimura T and Yamaguchi T 1987 in Advances in Ceramics (eds) G L Messing, K S Mazkiyasni, J W McCauley and R A Haber (Ohio: American Ceramic Society) 21

Knorr D B and Raeder C H 1990 in Superconduct. Appl. (ed.) H S Kwok (New York: Plenum Press) p. 621

Levin E M, Robbins C R and McMurdie H F 1969 in Phase diagrams for ceramics, 1969 supplement (ed.) M K Reser (Ohio: American Ceramic Society)

Lin S H, Swartz S L, Schulze W A and Biggers J V 1983 J. Am. Ceram. Soc. 66881

Ruckenstein E, Sanjeev N and Nae-Lih Wu 1989 J. Mater. Res. 4267 